\title{
Study on Thermal and Mechanical Properties of Biodegradable Blends of Poly ( $\varepsilon$-caprolactone) and Lignin
}

\author{
Jianchun LI, Yong He, and Yoshio INOUE ${ }^{\dagger}$ \\ Department of Biomolecular Engineering, Tokyo Institute of Technology, Nagatsuta \\ 4259, Midori-ku, Yokohama 226-8501, Japan
}

(Received November 9, 2000; Accepted January 17, 2001)

\begin{abstract}
The phase structure and physical property were investigated for blends of poly $(\varepsilon$-caprolactone) (PCL) and lignin, both of which were biodegradable polymers. The blend was prepared by mechanical mixing and solution casting. The thermal analysis (DSC and DMTA) indicated there was no detectable evidence that PCL/lignin blends prepared by mechanical mixing was miscible obviously. But it was found the obvious shift of glass transition temperature $T_{\mathrm{g}}$ of the blends prepared by solution casting. This was the strong evidence to support the fact that these two polymers were at least partially miscible. According to the results of FT-IR, no obvious changes in the shape and peak position of carbonyl absorption caused by formation of hydrogen bond between PCL carbonyl and lignin phenol hydroxyl groups were observed due to the fact that the number of phenol groups in lignin molecule is too small to induce detectable changes of carbonyl absorption. With increasing the lignin content in the blends, the position of $\mathrm{O}-\mathrm{H}$ stretching band obviously shifted from 3397 to $3412 \mathrm{~cm}^{-1}$. This shift to lower frequency was characteristic for intermolecular hydrogen bonding. Studying the mechanical property of the blends, we found that the maximum strength, elongation at maximum strength and elongation at break decreased but Young's modulus increased with the increasing content of lignin. Within the lignin content of $25 \%$, the material had good mechanical property. It was also found that the samples prepared by solution casting had better mechanical properties because of the higher dispersity. The result suggested that to blend PCL with lignin could contribute to increase Young's modulus and reduce the production cost of PCL materials.
\end{abstract}

KEY WORDS Poly ( $\varepsilon$-caprolactone) / Lignin / Biodegradable Polymer / Polymer Blends / Hydrogen Bond / Miscibility /

Most of traditional plastics are commonly made from fossil resources, that is, petroleum oil and are nonbiodegradable polymers. Using these non-biodegradable polymers in large scale has resulted in very serious environmental problems all over the world. At the same time, concepts such as "sustainable development" and "quality of life", combined with emerging regulatory requirements, have considerable impact on the responsibilities and activities of those involved in the protection of the environment. ${ }^{1}$

Growing environmental concerns have created an urgent need to develop new materials. Using biodegradable polymers to replace traditional oil-based plastics is one of ultimate available solutions to the environmental problems caused by the disposal of biostable plastic wastes. Of course, these biodegradable polymers should satisfy several requirements at first. They should be reasonably low in product cost, ${ }^{2}$ satisfactory in mechanical properties ${ }^{3}$ and not harmful to animals and plants when biodegraded. The biodegradation kinetics should be also an important issue of biodegradable plastics. ${ }^{4}$

However, there are not so many biodegradable polymers which accord with these demands. In fact, only a few aliphatic polymers, such as poly( $\varepsilon$-caprolactone), poly(lactic acid), poly(butylene succinate-co-butylene adipate), etc., are commercially available biodegradable polymers around the world now, and the others are thought unacceptable by several kinds of reasons. The output of these biodegradable polymers is very low compared with that of traditional polymers, but it is increasing rapidly every year.

In recent years, interest in polymer blends has been rising because blending is thought as an inexpensive and effective method for the modification of polymer properties. ${ }^{5}$ This strategy is usually cheaper and less time-consuming than the development of new polymers and/or new polymerization routes, as the basis for entirely new polymeric materials. ${ }^{6}$ Blend properties are governed by the types of the component polymers and interaction between them. ${ }^{7}$

A molecule with hydroxyl group is inclined to be able to interact with other molecules having hydrogenacceptable groups. Close attention has been paid to hydroxyphenyl-containing polymers and some additives, such as poly(4-vinylphenol) $(\mathrm{PVPh})^{8-16}$ and 4,4thiodiphenol (TDP), ${ }^{17-19}$ the hydroxyl groups of which have the potential ability to form strong intermolecular hydrogen bonds with carbonyl, ether, or other functional groups of the second polymers. ${ }^{20-22}$ It has been found that PVPh, as well as TDP, could modify the physical properties of polyesters by forming strong hydrogen bonds between phenolic hydroxyl groups of PVPh and TDP and ester carbonyl groups of polyesters. Usually, the strong intermolecular hydrogen bonds between two polymers increase the miscibility of the blends and are of benefit to the mechanical property. Hence, lignin, which has much phenol groups, is expected to be a good partner for polyester.

Studies on the utilization of lignin seem to be among the most challenge and promising area in natural polymers. Lignin is an abundant nontoxic amorphous natural polymer and an inexpensive by-product of the paper industry for which there is, at present, only a very small market around the world, ${ }^{23-24}$ but the rest is used al-

${ }^{\dagger}$ To whom correspondence should be addressed (Tel: +81-45-924-5794, Fax: +81-45-924-5827, E-mail: yinoue@bio.titech.ac.jp). 
most exclusively as fuel to generate energy. Its macromolecule is chemically complex and the main monomer units constituting lignin molecules are 2-methoxy-4propyl-phenol (guajacol) in soft wood and a mixture of 2methoxy-4-propyl-phenol (guajacol) and 1,5-dimethoxy4-propyl-phenol (syringol) in hardwood. ${ }^{25}$ These functional groups import a high polarity to the lignin macromolecule. Because of these characteristics, including its biodegradability, lignin is expected to be an extremely promising material as filler in the field of organic filler or as a chemical component in the polymer blends. Lignin helps to lower the cost of the finished product as well as giving some biodegradable characteristics to the thermoplastic polymers.

Poly ( $\varepsilon$-caprolactone) (PCL) is one of the current commercial biodegradable polymers. It is an aliphatic polyester aerobically degraded by a large number of microorganisms in various microbiological environments. But the price of PCL is much higher than that of traditional plastics, ${ }^{26}$ which limits its application.

The aim of this paper is to report various properties, including thermal and mechanical properties, of blends of PCL and lignin. Different ratios of PCL to lignin are tested, but in order to develop economically viable biodegradable thermoplastics, PCL should remain as the major phase in the blend $(>50 \%)$ and the percentage of lignin should be as high as possible.

\section{EXPERIMENTAL}

\section{Materials}

The PCL powder sample (Celgreen ${ }^{\circledR} \mathrm{PH} 4$, numberaverage molecular weight $=1.37 \times 10^{5}$; polydispersity index $=1.49$ ) was supplied by the courtesy of Daicel Co. (Japan). Lignin powder sample (Vanillex HW; Lot No. 98105152; weight-average molecular weight $=c a$. 5000) was kindly supplied by Nippon Paper Industries Co. Ltd.

\section{Preparation of the Blends}

The powders of dried lignin and PCL were weighted separately and placed in a mortar for thorough manual mixing during $5 \mathrm{~min}$. The powder mixture was subsequently compression moulded between Teflon sheets with an appropriate spacer for $5 \mathrm{~min}$ at $150^{\circ} \mathrm{C}$ under a pressure of $5 \mathrm{MPa}$, using a Toyoseiki laboratory press (Mini Test Press-10), followed by rapid cooling to room temperature between two iron plates. The blend samples (thickness: $0.2-0.3 \mathrm{~mm}$ ) were aged at room temperature for more than two weeks before physical characterization was attempted.

The film samples of homopolymer PCL and PCL/lignin blends were prepared by the conventional solvent (pyridine) casting using the glass petri dishes as the casting surfaces (thickness: $0.07-0.10 \mathrm{~mm}$ ), subsequently evaporated slowly and placed for further 5 days under vacuum to eliminate the solvent completely, and at last kept under ambient temperature for more than two weeks to allow crystallization of PCL to approach equilibrium before characterization.

\section{Differential Scanning Calorimetry (DSC)}

Differential scanning calorimetric thermograms were recorded on a SEIKO-DSC $220 \mathrm{U}$ as follows: about $5 \mathrm{mg}$ of a sample was encapsulated into an aluminum pan, and then heated from -100 to $200^{\circ} \mathrm{C}$ at a scanning rate of $20^{\circ} \mathrm{C} \mathrm{min}{ }^{-1}$ (first heating scan). The sample was rapidly quenched to $-120^{\circ} \mathrm{C}$, and re-heated from -100 to $200^{\circ} \mathrm{C}$ at a scanning rate of $10^{\circ} \mathrm{C} \mathrm{min}^{-1}$ (second heating scan). Melting points $T_{\mathrm{m}} \mathrm{s}$ (1st) were taken as endothermic peak tops in the thermal diagrams recorded by the first heating scan, and heat of fusion $\Delta H_{\mathrm{f}} \mathrm{s}$ (1st) was calculated from the integral of the endothermic melting peaks in DSC curves. Glass transition temperatures $T_{\mathrm{g}} \mathrm{S}$ (2nd) were taken as indicated by DDSC (differentiation of DSC) peak recorded by the second heating scan.

\section{Dynamic Mechanical Thermal Analysis (DMTA)}

Dynamic mechanical spectra were recorded on a SEIKO-DMS 210 instrument in the tensile mode. The DMTA spectra of test samples prepared via mechanical mixing (length, $30 \mathrm{~mm}$; width, about $10 \mathrm{~mm}$; thickness, $0.2-0.3 \mathrm{~mm}$ ) were measured from -100 to $60^{\circ} \mathrm{C}$ at a thermal scanning rate of $2^{\circ} \mathrm{C} \min ^{-1}$ at $0.5 \mathrm{~Hz}$. The peak observed in the loss tangent vs. temperature plot is associated with the glass transition in the amorphous regions.

\section{Fourier Transform Infrared (FT-IR)}

The thin layers of the blends with a suitable thickness for FT-IR measurements were prepared by the polymer solution in pyridine and directly dropped to the surface of silicon wafers. The silicon wafer, used as a substrate, was transparent for an IR incident beam. The maximum absorption of the resulting thin layers was lower than 1 absorbance unit, which ensured that all absorption was within the linearity range of the detector.

IR measurements were carried out on a single beam IR spectrometer (Perkin-Elmer Spectra 2000) at room temperature under $\mathrm{N}_{2}$ purging. All spectra were recorded at a resolution of $4 \mathrm{~cm}^{-1}$ and with an accumulation of 16 scans.

\section{Gel Permeation Chromatography (GPC)}

The molecular weight of PCL in pure state or in the blends prepared by mechanical mixing was characterized by a Tosoh HLC-8020 GPC system with TSK GEL $\mathrm{G} 2000 \mathrm{Hxl}$ and GMHxl columns. Chloroform was used as the eluant at a flowing rate of $1.0 \mathrm{~mL} \mathrm{~min}^{-1}$, and polystyrene with a narrow molecular distribution was used as a standard to calibrate the curve. Number average molecular weight $\left(M_{\mathrm{n}}\right)$, weight average molecular weight $\left(M_{\mathrm{w}}\right)$ and polydispersity $\left(M_{\mathrm{w}} / M_{\mathrm{n}}\right)$ were calculated from the GPC data through a SC-8010 data processor.

\section{Mechanical Property Testing}

Measurements of mechanical properties of specimens were performed at room temperature with a SHIMADZU (Japan) EZ Test machine at a cross-head speed of $5 \mathrm{~mm} \mathrm{~min}{ }^{-1}$. All samples had a gauge length of 22.25 $\mathrm{mm}$, and a gauge width of $4.76 \mathrm{~mm}$ with variable thickness in the range of $0.2-0.3 \mathrm{~mm}$. Each value reported is an average of three specimens. The Young's modulus was obtained from the tangent of the initial slope of force $v s$. elongation curve. 


\section{RESULTS AND DISCUSSION}

\section{DSC Analysis of PCL and PCL / Lignin Blends}

DSC is commonly used to provide some evidence of miscibility of polymer blends according to physical phenomena such as glass transition, melting, and crystallization. Usually, the observation of a single, compositiondependent glass transition temperature, $T_{\mathrm{g}}$, between those of the pure components is normally taken as an evidence of miscibility. ${ }^{27}$

In this study, lignin is an amorphous polymer, the glass transition of which cannot be detected by DSC. If the $T_{\mathrm{g}}$ observed has some distinct changes compared with that of PCL, the blends are thought partially miscible at least. It is also well known that the $T_{\mathrm{g}}$ is not so easy to measure for semi-crystalline polymer like PCL. In fact, the glass transition in the amorphous rigid interfacial region situated between the lamellar crystals and the amorphous phase is not observable or inaccurate even if observable by DSC in the usual conditions. In order to detect this parameter, two steps, as described in the experimental part, were used to decrease the influence of this interfacial region, which contained a high fraction of the total amorphous region.

Figures 1 and 2 showed the DSC curves of the samples of PCL and blends prepared by mechanical mixing. The DSC thermograms of PCL recorded during the first and the second heating scan present, respectively, two different thermal events: an endothermic peak at $57.8^{\circ} \mathrm{C}$ and an increase of heat capacity at $-61.8^{\circ} \mathrm{C}$. These events could be attributed to the melting of the crystalline domains and to the glass transition of the amorphous domains of the polymer, respectively. From these two figures, the $T_{\mathrm{m}}$ and $T_{\mathrm{g}}$ values were compared among the blends and pure PCL. It was not found any detectable changes for these two temperatures as shown in Figures 1, 2, and Table I. These results showed no effect of lignin on the thermal properties of PCL in the blend.
The degree of crystallinity of PCL, in the blends, $X^{*}$, was estimated from melting enthalpy, $\Delta H$, in the first scan and the reference melting enthalpy of $100 \%$ crystalline PCL, $\Delta H_{\text {ref }}$, via $X^{*}=\Delta H /\left(W_{\mathrm{PCL}} \Delta H_{\text {ref }}\right)$, where $W_{\mathrm{PCL}}$ is the weight fraction of PCL and $\Delta H_{\text {ref }}=136.1 \mathrm{~J} \mathrm{~g}^{-1}{ }^{28}$ The calculated value of crystallinity of pure PCL was similar to what had been reported in some papers. ${ }^{17,28-29}$ When PCL was blended with different ratio of lignin, the crystallinity kept about 50\%. From the Table I, it could be concluded that the PCL crystallinity did not change significantly. It indicated that lignin has no detectable effect on the solid-state structure of PCL.

Figures 3, 4, and Table II showed the results of the DSC analysis of blend films prepared by casting pyridine solution. It was found that the $T_{\mathrm{g}}$ of PCL in the blends had obvious shift, from $-60.0^{\circ} \mathrm{C}$ (pure PCL) to $-52.9^{\circ} \mathrm{C}$ (lignin $40 \%$-PCL). The increase in $T_{\mathrm{g}}$ should be caused

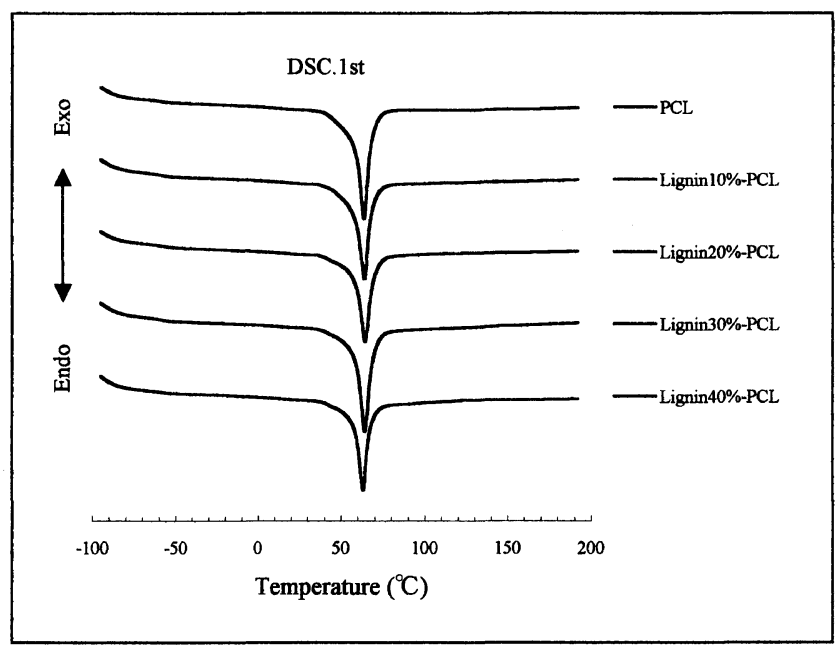

Figure 1. The DSC traces of PCL and its blends with various lignin contents recorded during the first heating scan. The blend samples were prepared by mechanical mixing.

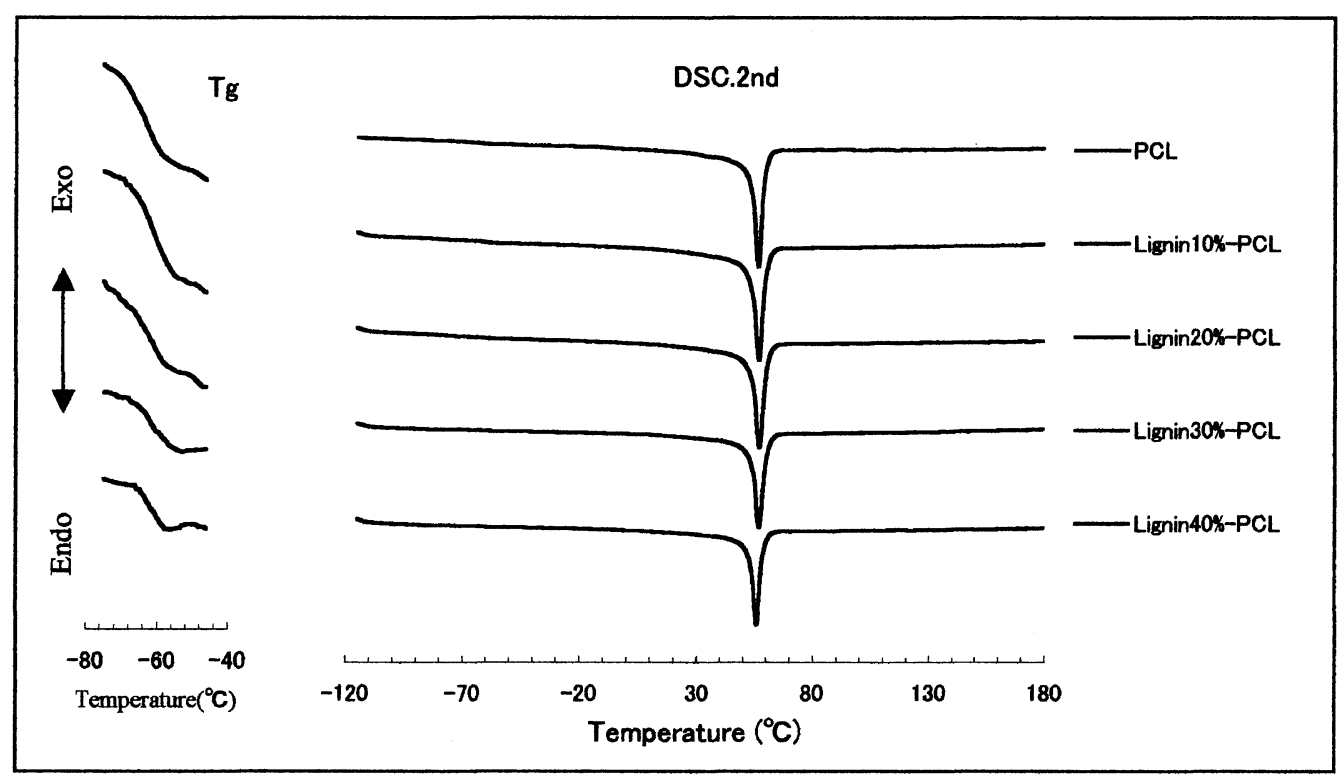

Figure 2. The DSC traces (right hand side) and their amplification of the area near $T_{\mathrm{g}}$ (left hand side) of PCL and its blends with various lignin contents recorded during the second heating scan. The blend samples were prepared by mechanical mixing. 


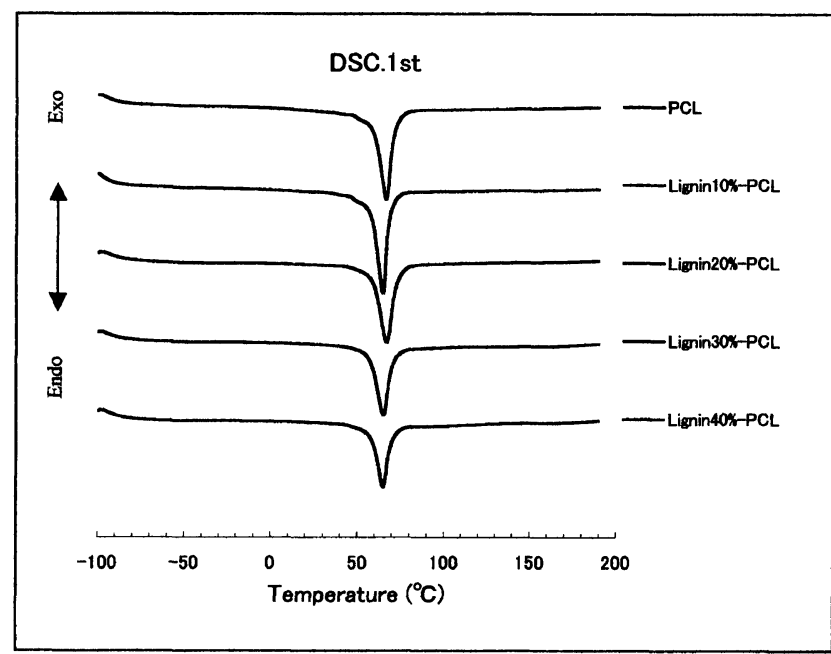

Figure 3. The DSC traces of PCL and its blends with various lignin contents recorded during the first heating scan. The blend samples were prepared by casting from pyridine solutions. by interaction between PCL and lignin. A probable interaction is the formation of hydrogen bonds between the carbonyl groups in PCL and the phenol hydroxyl groups in lignin. It has been reported that the phenolic hydroxyl group has the potential ability to form strong intermolecular hydrogen bond with the ester carbonyl group..$^{8-19}$ The formation of hydrogen bonds induced the compatibilization between PCL and lignin although the values of $T_{\mathrm{m}}$ and crystallinity of PCL kept almost constant and even higher than those of the blend samples prepared by mechanical mixing.

When we compared Tables I and II, the difference of thermal properties between the blends prepared by mechanical mixing and by solution casting were obvious, from which we got different conclusions that seemed contradictory. It could be explained that the solution casting made the two component polymers molecular level blend and mixing mechanically could not arrive at

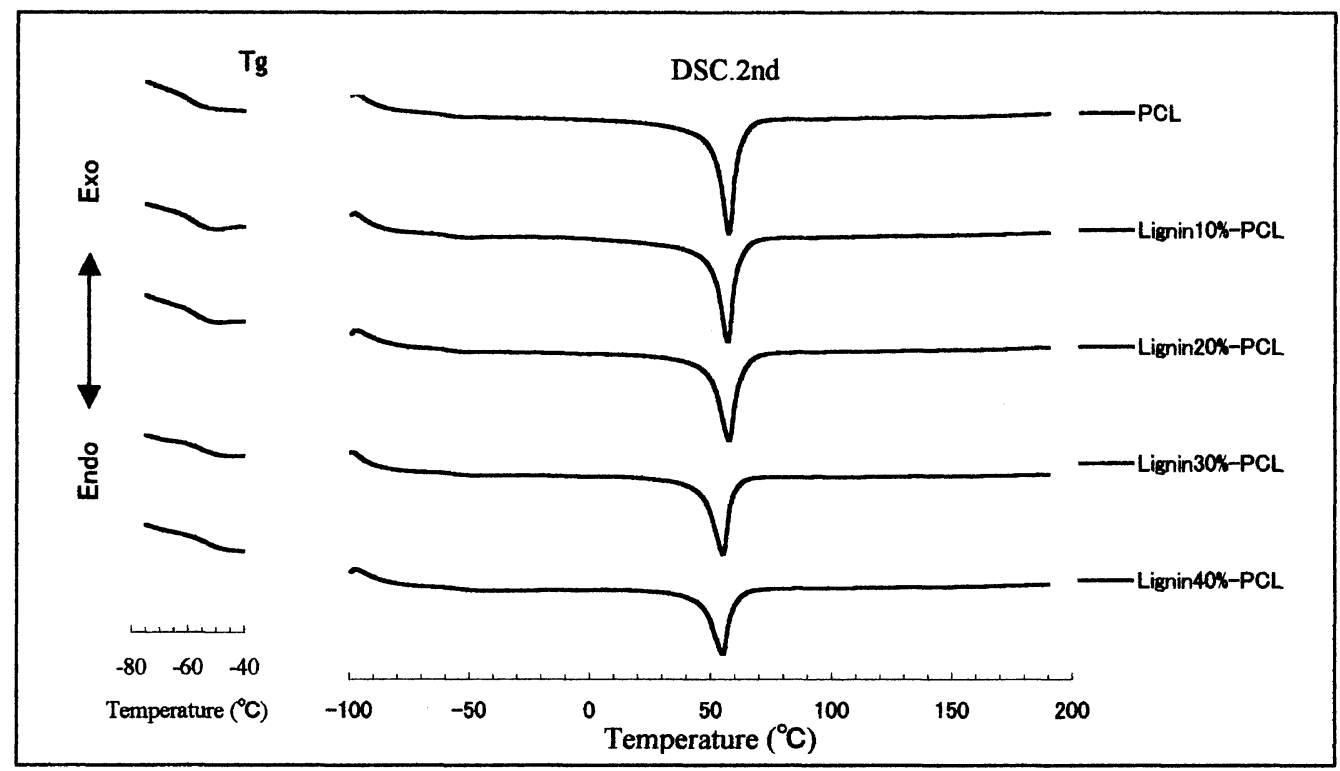

Figure 4. The DSC traces (right hand side) and their amplification of the area near $T_{\mathrm{g}}$ (left hand side) of PCL and its blends with various lignin contents recorded during the second heating scan. The blend samples were prepared by casting from pyridine solutions.

Table I. The thermal properties and degree of crystallinity of PCL in the blends with lignin prepared by mechanical mixing

\begin{tabular}{lcccc}
\hline Sample & $T_{\mathrm{m}} /{ }^{\circ} \mathrm{C}^{\mathrm{a}}$ & Melting enthalpy $/ \mathrm{J} \mathrm{g}^{-1}$ & Crystallinity $/ \%^{\mathrm{b}}$ & $T_{\mathrm{g}} /{ }^{\circ} \mathrm{C}^{\mathrm{c}}$ \\
\hline PCL & 57.5 & 67.2 & 49.4 & -61.8 \\
Lignin 10\%-PCL & 57.8 & 59.3 & 48.4 & -59.7 \\
Lignin 20\%-PCL & 57.5 & 54.5 & 50.1 & -61.3 \\
Lignin 30\%-PCL & 57.9 & 50.5 & 53.0 & -60.4 \\
Lignin 40\%-PCL & 56.2 & 43.7 & 53.6 & -60.3 \\
\hline
\end{tabular}

${ }^{a}$ Obtained from the DSC first heating scan. ${ }^{\mathrm{b}}$ Calculated from the melting enthalpy of the PCL component (the area of the DSC melting peak in the first heating scan), with the melting enthalpy of $100 \%$ crystalline PCL assumed to be $136.1 \mathrm{Jg} \mathrm{g}^{-1}{ }^{28}{ }^{\mathrm{c}}$ Obtained from the second heating scan.

Table II. The thermal properties and degree of crystallinity of PCL in the blends with lignin prepared by solution casting

\begin{tabular}{|c|c|c|c|c|}
\hline Sample & $T_{\mathrm{m}} /{ }^{\circ} \mathrm{C}^{\mathrm{a}}$ & Melting enthalpy/ $\mathrm{J} \mathrm{g}^{-1}$ & Crystallinity/\% ${ }^{\mathrm{b}}$ & $T_{\mathrm{g}} /{ }^{\circ} \mathrm{C}^{\mathrm{c}}$ \\
\hline PCL & 66.2 & 89.8 & 66.0 & -60.0 \\
\hline Lignin $10 \%-P C L$ & 62.9 & 81.8 & 66.8 & -57.9 \\
\hline Lignin $20 \%$-PCL & 66.9 & 73.8 & 67.8 & -56.9 \\
\hline Lignin 30\%-PCL & 64.6 & 64.9 & 68.1 & -54.8 \\
\hline Lignin $40 \%$-PCL & 65.5 & 55.3 & 67.7 & -52.9 \\
\hline
\end{tabular}

${ }^{\mathrm{a}}$ Obtained from the DSC first heating scan. ${ }^{\mathrm{b}}$ Calculated from the melting enthalpy of the PCL component (the area of the DSC melting peak in the first heating scan), with the melting enthalpy of $100 \%$ crystalline PCL assumed to be $136.1 \mathrm{~J} \mathrm{~g}^{-1} .^{28}{ }^{\mathrm{c}}$ Obtained from the second heating scan. 
this molecular level, but only at macroscopic level. At the same time, another reason, the decrease of molecular weight of PCL in mechanical mixing samples according to Figure 9, should be paid attention. It was different molecular weight of PCL and thermal history of samples that contribute to thermal property changes of PCL.

\section{Dynamic Mechanical Relaxation Behavior}

The $\tan \delta$ peak of DMTA thermograms also provided a feasible method to measure the $T_{\mathrm{g}}$ value. The temperature $v s$. storage modulus $\left(E^{\prime}\right)$ and $\tan \delta$ curves for pure PCL were typical for PCL as shown in Figure 5. The glass transition appeared at $-60.0^{\circ} \mathrm{C}$, which was almost the same as that observed by DSC. The $E^{\prime}$ curve was relatively constant over broad range from the temperature that correlates to the onset of the glass transition up to the temperature just below the melting point.

As shown in Figure 6, DMTA data, comparing the
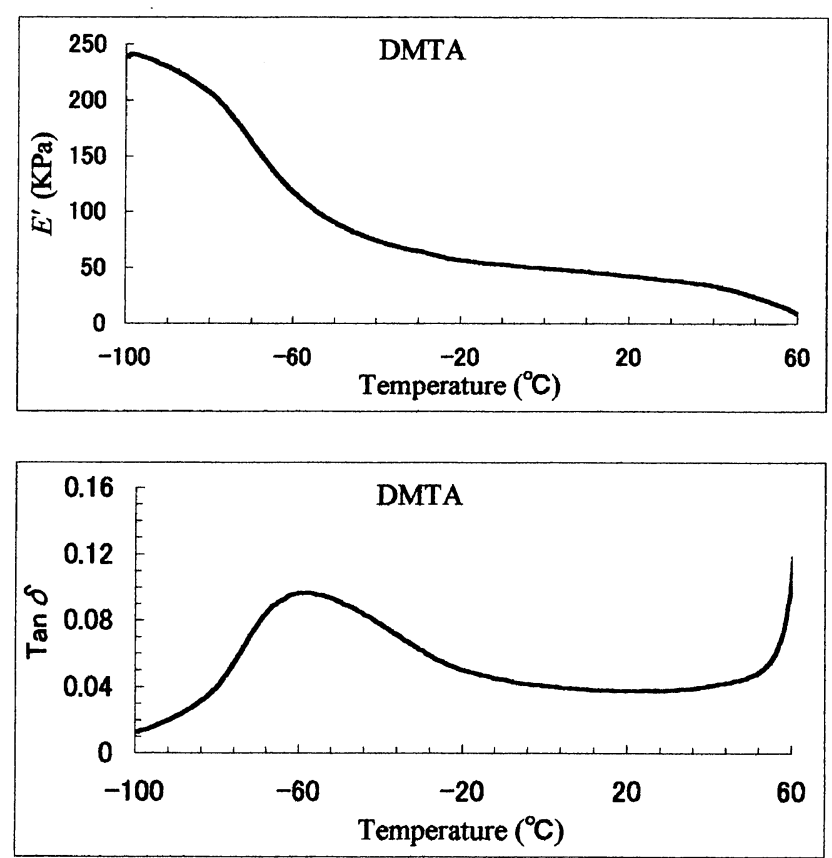

Figure 5. The DMTA thermogram of PCL.

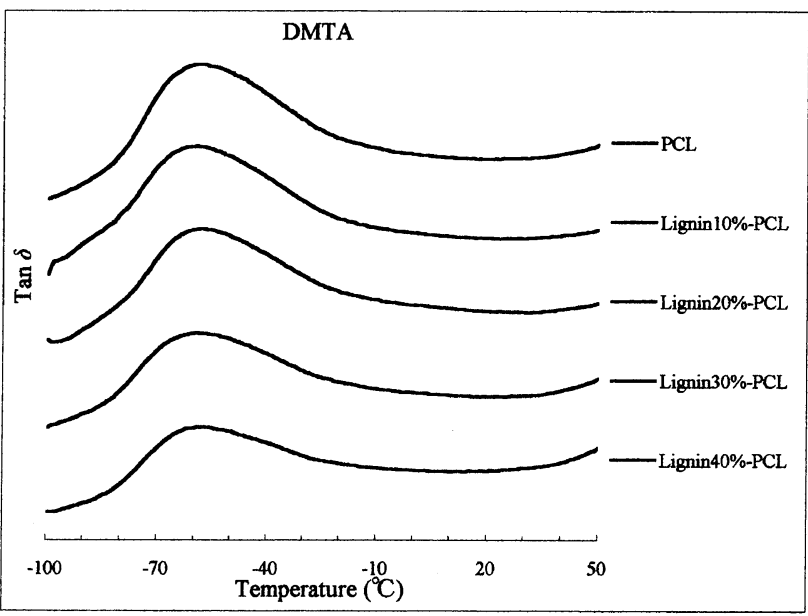

Figure 6. The DMTA thermograms of PCL and its blends with lignin prepared by mechanical mixing. $\tan \delta$ peaks from PCL and the PCL/10-40\% lignin blends prepared by mechanical mixing, showed no significant shift or changes in the shape of this peak after blending with lignin. Likewise, there were no evident changes in the loss modulus ( $\left.E^{\prime \prime}\right)$ for all of the blends prepared by mechanical mixing. These results implied no detectable changes of PCL glass transition temperature $\left(T_{\mathrm{g}}\right)$, and hence no significant thermodynamic compatibility between PCL and lignin. This conclusion is identical to that obtained from DSC.

FT-IR Analysis of Lignin, PCL and Their Blends Prepared from Solution

The FT-IR spectra of the thin layers of lignin, PCL and their binary blends prepared from pyridine solution were recorded in the range of 4000 to $600 \mathrm{~cm}^{-1}$, as shown in Figures 7 and 8.

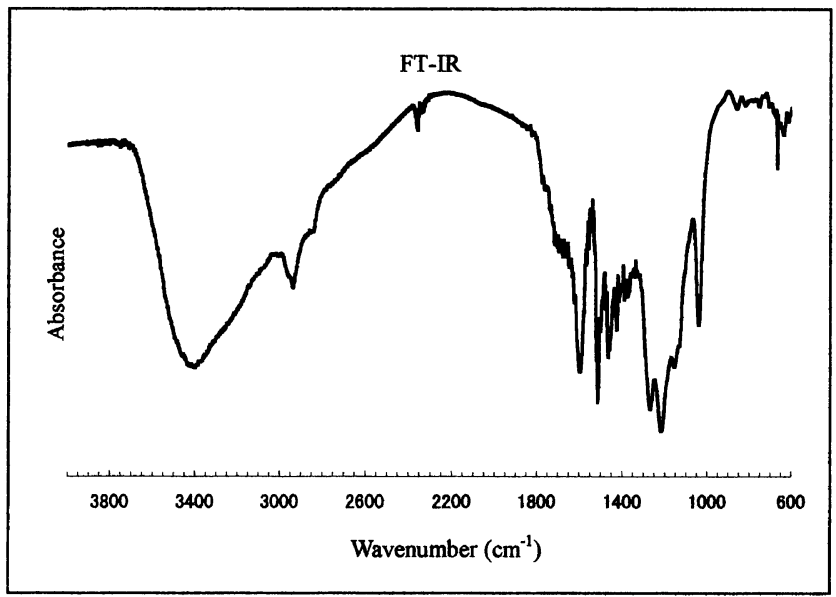

Figure 7. The FT-IR spectra in the $4000-600 \mathrm{~cm}^{-1}$ region for lignin films prepared from pyridine solution.

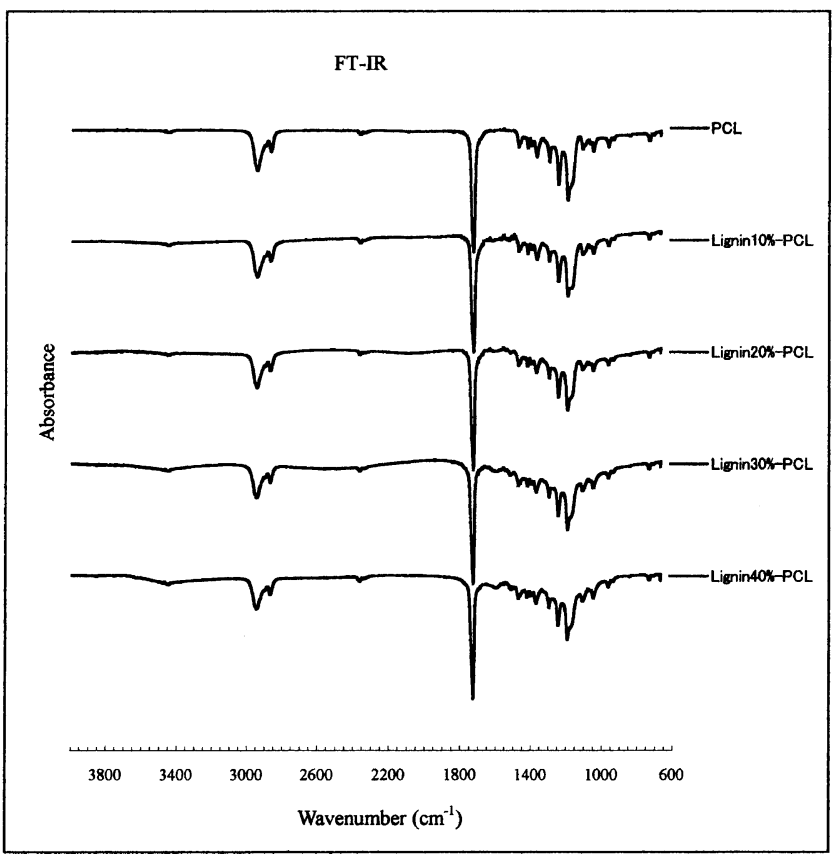

Figure 8. The FT-IR spectra in the $4000-600 \mathrm{~cm}^{-1}$ region for PCL and PCL/lignin blends prepared from pyridine solution. 
In the spectra of lignin (Figure 7), the band near 3400 $\mathrm{cm}^{-1}$ was due to the hydroxyl groups of the lignin, i.e., $\mathrm{O}-\mathrm{H}$ stretching. The absorption bands from 3100 to 2900 $\mathrm{cm}^{-1}$ represented all kinds of $\mathrm{C}-\mathrm{H}$ bands. The visible broad shoulder near $2850 \mathrm{~cm}^{-1}$ was assignable to the methoxyl groups, but they were so weak. The band from 1735 to $1715 \mathrm{~cm}^{-1}$ was due to the acetyl groups, which were attached to lignin molecule. Usually lignin shows these characteristic IR peaks.

In the spectrum of pure PCL (Figure 8 top), the absorption band of hydroxyl $\mathrm{O}-\mathrm{H}$ stretching near 3400 $\mathrm{cm}^{-1}$ was not so strong. It was attributed to the lowconcentration hydroxyl chain-end groups of PCL. With the increasing content of lignin in the blend, the absorption intensity of hydroxyl $\mathrm{O}-\mathrm{H}$ stretching band increased but was still weak. It was found that, as one of the main characteristics of FT-IR spectra of the blends in comparision with the spectra of pure lignin and PCL, the peak position of $\mathrm{O}-\mathrm{H}$ stretching band shifted obviously from 3397 to $3412 \mathrm{~cm}^{-1}$. This shift to lower frequency was characteristic for intermolecular hydrogen bonding.

The carbonyl absorption of PCL, which is the most significant characteristic peak of PCL, is composed of a maximum situated at $1724 \mathrm{~cm}^{-1}$ associated with the crystalline part of the polymer and of a shoulder at 1731 $\mathrm{cm}^{-1}$ corresponding to the amorphous fraction. ${ }^{30}$ It has been reported that the IR carbonyl absorption of polyesters including PCL show large shift by forming intermolecular hydrogen bond with phenol hydroxyl group..$^{8-19}$ As shown in the Figure 8, no obvious changes in the shape and peak position of carbonyl absorption caused by formation of hydrogen bond between PCL carbonyl and lignin phenol hydroxyl groups were observed. This result may be due to the fact that the number of phenol groups in lignin molecule is too small to induce detectable changes of carbonyl absorption.

\section{Mechanical Properties of PCL and PCL/Lignin Blends}

Mechanical properties such as Young's modulus $(E)$, maximum strength $\left(\sigma_{\max }\right)$, elongation at maximum strength $\left(\varepsilon_{\max }\right)$ and elongation at break $\left(\varepsilon_{\mathrm{b}}\right)$ were evaluated from the stress-strain curves. The experimental results were presented in Table III for the samples prepared by mechanical mixing.

According to the data, it is obvious that the PCL, as well known, is a ductile polymer with significantly large elongation at break, able to undergo large deformations. Unfortunately, it possesses a relatively low modulus, which renderes its applications in many cases where a high rigidity is required. Therefore, the addition of lig- nin phase in the blends prepared by mechanical mixing could improve its Young's modulus of PCL significantly, just as we expected, increasing it until more than twice (448 MPa for the blend PCL/lignin 60/40 against 223 $\mathrm{MPa}$ for PCL). Even though as a consequence all other mechanical parameters were reduced,the blends, whose contents of lignin were not more than $25 \%$, have acceptable mechanical properties with respect to neat PCL. The reductions of mechanical properties of the blends were due to the fact that the presence of lignin particles, which were not capable of being deformed, prevent the formation of the long-range continuous phase of PCL drawn at room temperature. On the other hand, preparing process at high temperature made PCL decomposed. The molecular weight was measured for pure PCL and PCL extracted with chloroform from PCL/lignin blends which were prepared by mechanical mixing at $150^{\circ} \mathrm{C}$ for $5 \mathrm{~min}$. The values of number-average molecular weight $M_{\mathrm{n}}$ and polydispersity index $M_{\mathrm{w}} / M_{\mathrm{n}}$ of pure PCL used in this experiment were respectively $1.37 \times 10^{5}$ and 1.49 . After the processing at $150^{\circ} \mathrm{C}$ for $5 \mathrm{~min}$, they became $1.13 \times 10^{5}$ and 1.66 , respectively. With increasing lignin content, the molecular weight of PCL decreased obviously, as shown in Figure 9. When the lignin content was $40 \%$, the molecular weight of PCL was only $0.61 \times$ $10^{5}$. The existence of lignin accelerates the decomposition speed of PCL at high temperature. It was well known that the molecular weight of polymer had important influence on its mechanical property.

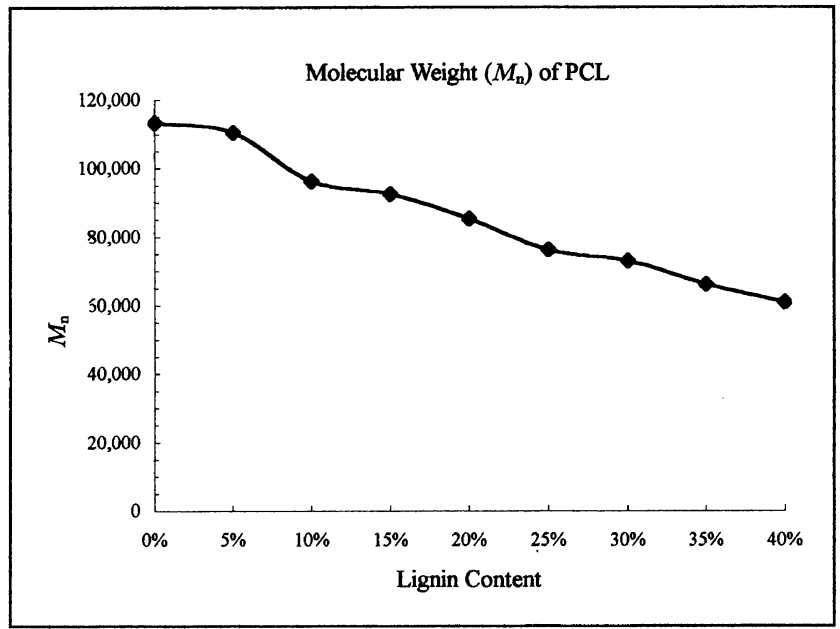

Figure 9. Number-average molecular weight of PCL and PCL extracted with chloroform from the blends which were prepared by mechanical mixing at $150^{\circ} \mathrm{C}$ for $5 \mathrm{~min}$.

Table III. Mechanical properties of PCL and the blends with lignin prepared by mechanical mixing

\begin{tabular}{|c|c|c|c|c|}
\hline \multirow{2}{*}{ Samples } & Maximum strength $\left(\sigma_{\max }\right)$ & Elongation at maximum strength $\left(\varepsilon_{\max }\right)$ & $\underline{\text { Elongation at break }\left(\varepsilon_{\mathrm{b}}\right)}$ & Young's modulus $(E)$ \\
\hline & $\mathrm{N} \mathrm{mm}^{-2}$ & $\begin{array}{l}\mathrm{mm} \\
\end{array}$ & $\%$ & $\mathrm{~N} \mathrm{~mm}^{-2}$ \\
\hline PCL & 36.0 & 183 & 844 & 223 \\
\hline Lignin 5\%-PCL & 24.6 & 147 & 668 & 257 \\
\hline Lignin 10\%-PCL & 15.1 & 92.9 & 429 & 278 \\
\hline Lignin 15\%-PCL & 12.2 & 72.5 & 355 & 279 \\
\hline Lignin $20 \%$-PCL & 11.1 & 74.1 & 349 & 279 \\
\hline Lignin 25\%-PCL & 9.9 & 56.3 & 283 & 292 \\
\hline Lignin 30\%-PCL & 9.8 & 17.2 & 170 & 315 \\
\hline Lignin 35\%-PCL & 7.4 & 8.9 & 70 & 418 \\
\hline Lignin $40 \%-\mathrm{PCL}$ & 6.9 & 5.5 & 55 & 448 \\
\hline
\end{tabular}


Table IV. Mechanical properties of PCL and PCL/lignin blends prepared by casting from pyridine solutions

\begin{tabular}{lccccc}
\hline \multirow{2}{*}{ Samples } & Maximum strength $\left(\sigma_{\max }\right)$ & Elongation at maximum strength $\left(\varepsilon_{\max }\right)$ & Elongation at break $\left(\varepsilon_{\mathrm{b}}\right)$ & \multicolumn{2}{c}{ Young's modulus $(E)$} \\
\cline { 2 - 3 } & $\mathrm{N} \mathrm{mm}^{-2}$ & 172 & 781 & $\mathrm{~N} \mathrm{~mm}^{-2}$ \\
\hline PCL & 28.4 & 161 & 724 & 254 \\
Lignin 5\%-PCL & 32.1 & 150 & 669 & 288 \\
Lignin 10\%-PCL & 25.6 & 135 & 612 & 311 \\
Lignin 15\%-PCL & 21.9 & 67 & 311 & 366 \\
Lignin 20\%-PCL & 14.6 & & 389 \\
\hline
\end{tabular}

Mechanical properties of the samples prepared by solution casting were shown in Table IV. When the content of lignin in the blends was more than $20 \%$, we could not get the films suitable for mechanical testing due to the poor compatibility between PCL and lignin. The mechanical properties of the samples prepared by solution casting, similar to those of samples prepared by mechanical mixing, showed lignin-content dependent changes. But, it was worthy to note that, with increasing content of lignin in the blends, Young's modulus of the blends prepared by solution casting increased more rapidly compared with the samples prepared by mechanical mixing. The elongation at break of the samples decreased slightly. When the content of lignin was up to $20 \%$, it reduced to $311 \%$ only. Even the mechanical properties of pure PCL samples prepared by different procedures had distinct changes according to Tables III and IV, which could be attributed to the decrease of molecular weight of PCL in mechanical mixing samples according to Figure 9. At the same time, the higher dispersity of lignin in the solution casting blends made the blends possess better mechanical properties than that of the mechanical mixing blends.

\section{CONCLUSIONS}

The thermal and mechanical properties of the blends of PCL and lignin, prepared by mechanical mixing and solution casting, were studied.

The results of DSC and DMTA analyses could not provide any obvious evidences which showed the miscibility of PCL and lignin in the blends prepared by mechanical mixing. The glass transition temperature, the melting temperature and the crystallinity of pure PCL and the PCL in the blends kept almost constant. At the same time, an opposite conclusion that the miscibility existed between PCL and lignin had been got for the blend samples prepared by casting pyridine solutions, as we found obvious changes of $T_{\mathrm{g}}$ of PCL in these blend samples although $T_{\mathrm{m}}$ and crystallinity of PCL kept almost constant.

The FT-IR spectra indicated no obvious changes in the shape and peak position of carbonyl absorption caused by the formation of hydrogen bond between the PCL carbonyl and the lignin phenol hydroxyl groups. This is due to the fact that the number of phenol groups in lignin molecule is too small to induce detectable changes of carbonyl absorption. But an obvious shift was found in the position of $\mathrm{O}^{-} \mathrm{H}$ stretching band from 3397 to $3412 \mathrm{~cm}^{-1}$. This shift to lower frequency was characteristic for intermolecular hydrogen bonding.

The mechanical properties of the PCL and lignin blends prepared by mechanical mixing were investi- gated. The Young's modulus $(E)$ of the blends increased significantly with increasing lignin content in the blends. Thus, the addition of lignin to PCL can remedy the defect of PCL, which possesses a relatively low modulus, although some other performance parameters, such as maximum strength $\left(\sigma_{\max }\right)$, elongation at maximum strength $\left(\varepsilon_{\max }\right)$ and elongation at break $\left(\varepsilon_{\mathrm{b}}\right)$, decreased when the content of lignin is within $25 \%$. Similar conclusion could be obtained from the sample prepared by solution casting.

Acknowledgment. The authors thank Daicel Co. and Nippon Paper Industries Co. Ltd. for the kind gift of PCL and lignin samples, respectively.

\section{REFERENCES}

1. E. Green, S. D. Short, E. Stutt, and P. T. C. Harrison, Sci. Total Environ., 256, 205 (2000).

2. W. Amass, A. Amass, and B. Tighe, Polym. Int., 47, 89 (1998).

3. Y. Inoue and N. Yoshie, Prog. Polym. Sci., 17, 571 (1992).

4. Y. Ikada and H. Tsuji, Macromol. Rapid Commun., 21, 117 (2000).

5. S. L. Ciemniecki and W. G. Glasser, Polymer, 29, 1021 (1988).

6. C. Koning, M. V. Duin, C. Pagnoulle, and R. Jerome, Prog. Polym. Sci., 23, 707 (1998).

7. S. L. Ciemniecki and W. G. Glasser, Polymer, 29, 1030 (1988).

8. Y. Liu, S. H. Goh, S. Y Lee, and C. H. A. Huan, Macromolecules, 32, 1967 (1999).

9. L. Li, C. M. Chan, L. T. Weng, M. L. Xiang, and M. Jiang, Macromolecules, 31, 7248 (1998).

10. M. Hosokawa and S. Akiyama, Polym. J., 31, 13 (1999).

11. D. Li and J. Brisson, Macromolecules, 29, 868 (1996).

12. C. J. Serman, P. C. Painter, and M. M. Coleman, Polymer, 32, 1049 (1991).

13. D. J. T. Hill, A. K. Whittaker, and K. W. Wong, Macromolecules, 32, 5285 (1999).

14. H. L. Chen, S. F. Wang, and T. L. Lin, Macromolecules, 31, 8924 (1998).

15. L. L. Zhang, S. H. Goh, and S. Y. Lee, J. Appl. Polym. Sci., 70, 811 (1998).

16. J. Dong and Y. Ozaki, Macromolecules, 30, 286 (1997).

17. Y. He, N. Asakawa, and Y. Inoue, J. Polym. Sci., Part B: Polym. Phys., 38, 1848 (2000).

18. Y. He, N. Asakawa, and Y. Inoue, J. Polym. Sci., Part B: Polym. Phys., 38, 2891 (2000).

19. Y. He, N. Asakawa, and Y. Inoue, Macromol. Chem. Phys., in press.

20. M. M. Coleman and P. C. Painter, Prog. Polym. Sci., 20, 1 (1995).

21. G. J. Pehlert, P. C. Painter, and M. M. Coleman, Macromolecules, 31, 8423 (1998).

22. L. Li, C. M. Chan, L. T. Weng, M. L. Xiang, and M. Jiang, Macromolecules, 31, 7248 (1998).

23. D. Feldman, D. Banu, C. Luchian, and J. Wang, J. Appl. Polym. Sci., 42, 1537 (1991).

24. I. Simionescu, V. Rusan, M. M. Macoveanu, G. Cazacu, R. Lipsa, C. Vasile, A. Stoleriu, and A. Ioanid, Composites Sci. Tech., 48, 317 (1993). 
25. B. O. Myrvold and D. Pavlov, J. Powder Sources, 85, 92 (2000).

26. A. K. Mohanty, M. A. Khan, S. Sahoo, and G. Hinrichsen, J. Mater. Sci., 35, 2589 (2000).

27. G. Bisso, P. Casarino, and E. Pedemonte, Thermochimica Acta, 321, 81 (1998)
28. F. B. Khambatta, F. Warner, T. Russel, and R. S. Stein, J. Polym. Sci., Part B: Polym. Phys., 14, 1391 (1976).

29. Y. He and Y. Inoue, Polym. Int., 49, 623 (2000).

30. C. D. Kesel, C. Lefèvre, J. B. Nagy, and C. David, Polymer, 40, 1969 (1999). 